\title{
Влияние акустического замораживания на показатели структуры сублимированной клубники
}

\author{
Семёнов Геннадий Вячеславович \\ ФГБОУ ВО «Московский государственный университет пищевых производств» \\ Адрес: 125080, город Москва, Волоколамское шоссе, дом 11 \\ E-mail:sgv47@yandex.ru
}

Краснова Ирина Станиславовна

ФГБОУ ВО «Московский государственный университет пищевых производств» Адрес: 125080, город Москва, Волоколамское шоссе, дом 11

E-mail: ira3891@mail.ru

\begin{abstract}
Хвыля Сергей Игоревич
Всероссийский научно-исследовательский институт холодильной промышленности - филиал ФГБНУ «Федеральный научный центр пищевых систем им. В.М. Горбатова» $Р А Н$ Адрес: 127422, город Москва, ул. Костякова, дом 12 E-mail:gistolab@yandex.ru
\end{abstract}

\section{Балаболин Дмитрий Николаевич \\ ООО «Акустическая заморозка»} Адрес: 109316, город Москва, ул. Талалихина, дом 31 E-mail:dbalabolin@gmail.com

\begin{abstract}
Исследование посвящено вопросам изменения структуры клубники, предварительно замороженной традиционным способом в условиях естественной конвекции или замороженной с наложением микровибрации. Микровибрацию создавали в воздушной среде морозильной камеры в лабораторном устройстве ABAT-20/1-AEF, оснащенным цифровым синтезатором частот оригинальной конструкции, с генерации электромагнитных полей мощностью от 1 до 500 Вт/м ${ }^{3}$ с пакетами одно и двух полярных прямоугольных импульсов в диапазонах частот 10 мГц - 5000 кГц. Замороженные в двух вариантах ягоды подвергали вакуумной сублимационной сушке на оригинальном лабораторном стенде СВП-0,36. Температура сублимации составляла минус $30+1^{\circ} \mathrm{C}$, на этапедосушкитемпература была равной $38-40^{\circ} \mathrm{C}$. Общаядлительность цикла высушивания составила 14-16 часов в зависимости от размера ягод. Ягоды сушили до конечной влажности 1,7\%. В высушенных образцах изучали микроструктуру и оценивали показатели пенетрации, предельного напряжения сдвига, водопоглощения, определяли сорбционные свойства и органолептические показатели. Отмечено, что наложение микровибрации позволяет формировать мелкокристаллическую структуру льда и обеспечивать сохранность тканевых структур в высушенных продуктах. Исследования микроструктуры показали, что уровень сохранности клеточных структур при наложении микровибрации составляет 60-70\%, в сопоставлении с 25-30\% при традиционном замораживании. Выявлено, что применение микровибрации в процессах замораживания позволяет улучшить структурно-механические характеристики высушенных ягод клубники и их сохранность в процессе фасовки и транспортировки. Органолептические показатели у исследуемых образцов при двух вариантах замораживания остаются практически одинаковыми. В результате проведенных исследований отмечено, что наибольший эффект от наложения микровибраций отмечен для ягод меньшего размера.
\end{abstract}

Ключевые слова: микровибрация; клубника; вакуумная сублимационная сушка; микроструктура; структурномеханические показатели; сорбционные свойства 


\section{Введение}

В настоящее время признано, что вакуумная сублимационная сушка является одним из лучших методов удаления влаги и получения готового продукта высшего качества и длительного хранения (Дондокова, Битуева, Антипов, 2016, с.37-48.; Овчарова, Абреч, Непорожняя, 2008, с.1415; Христюк, Сязин, Мякинникова, 2014, с.78-80; Marques, Silveira, Freire, 2006, с. 457-463). В пищевой промышленности наиболее широко этот метод применяют для получения высококачественных быстрорастворимых сортов кофе и цикория, для сушки заквасок молочнокислых микроорганизмов и различных ферментов. (Похиленко, Баранов, Детушев, 2009, с. 99-121.; Burmester, Pietsch, Eggers, 2011, c. 1344 - 1352.; Gaidhani, Harwalkar, Bhambere, Nirgude, 2015, с. 516-543.). Тем не менее, вакуумная сублимационная сушка обладает огромным потенциалом для развития в нашей стране и для консервирования других пищевых продуктов.

Современный потребитель требует более высокое качество продуктов питания. Вакуумная сублимационная сушка, не смотря на высокое качество готовой продукции, всё ещё остается дорогостоящим и длительным методом, и высокие затраты на организацию процесса производства ограничивают её широкое применение в промышленных масштабах в пищевой промышленности. В связи с чем, проводят большое количество исследований в нашей стране и в мире по оптимизации процесса замораживания и сублимационной сушки, сокращению времени сушки и получению продукта заданного уровня качества (Крумликов, Остроумов, Сухих, Кригер, 2016, с. 25-30.; Семёнов, Булкин, Кузенков, 2015, c. 187-202.; Kozak, Dziki, Krzykowski, Rudy, 2011, c. 134-141.; Koroishi, Boss, Wolf Maciel, Filho, 2009, c. 425-441.; Tarafdar, Shahi, Singh, Sirohi, 2017, c.16; Salazar, Alvarez, Orrego, 2018, c. 192-204.).

Как известно, решающее влияние на показатели качества сублимированных продуктов и интенсивность последующего процесса обезвоживания оказывает замораживание. На этапе замораживания формируется кристаллическая структура, при этом форма и размер кристаллов льда, их распределение в замороженном материале, изменение физикохимических показателей зависит от режимных параметров процесса и свойств объектов замораживания. Вопросам замораживания в технологии консервирования термолабильных материалов и использованию вакуумной сублимационной сушки посвящена обширная литература (Постольски, Груда, 1974, 607 с.; Семёнов, Краснова, 2018, 292 с.; Ишевский, Давыдов, 2007, с. 43-59.; Колодязная, Кипрушкина, Бараненко, Румянцева, Шестопалова, 2013, с. 2428.; Воскобойников, 2015, с. 21-23.; Ciurzyńska, Lenart, 2011, c. 165-171; Rey, May, 2001, c. 163-164). Однако до сих пор вопросы получения более мелких однородных кристаллов, способных сохранить клеточные структуры остаются актуальными. Особенно это относится к фруктам и ягодам с нежной структурой, например, землянике садовой (клубнике). Более жесткие и плотные ягоды, лучше подвергаются обработке и транспортировке и имеют более длительный срок хранения и более привлекательный внешний вид, чем мягкоплодные ягоды. В связи с этим, актуальным является поиск различных методов, обеспечивающих более плотную структуру при замораживании и последующей обработке ягод.

На современном этапе наиболее распространенным методом обеспечения мелкокристаллической структуры в замораживаемых объектах является применение метода «шоковой заморозки». Он достигается использованием высоких скоростей воздуха (более $10 \mathrm{~m} / \mathrm{c}$ ) в низкотемпературных морозильных камерах с температурой воздуха на уровне минус 40 - 450С. Оборудование для шоковой заморозки достаточно сложное и дорогостоящее. Его применение требует высоких затрат электроэнергии и способствуют усушке продукта (Сороко, Усеня, 2011, с. 63-67.; Беляева, 2017, c. 40-43.; Celli, Ghanem, Su-Ling Brooks, 2017, с. 280-304.) Альтернативным методом формирования мелкокристаллической структуры может являться воздействие микровибрацией на ягоды при замораживании. В связи с чем, целью исследования являлось оценить влияние микровибрации на структурные показатели замороженной и сублимированной клубники.

В соответствие с целью в исследовании поставлены следующие задачи:

- определить влияние микровибрации на микроструктуру замороженной и высушенной сублимационной сушкой клубники.

- исследовать влияние микровибрации на показатели пенетрации и предельного напряжения сдвига замороженной и высушенной сублимационной сушкой клубники.

- оценить сорбционные свойства сублимированной клубники после обработки 
микровибрацией.

\section{Материалы и методы}

\section{Объекты и методы исследования}

Объектом исследований являлись ягоды земляники садовой (клубники) (лат. «Fragaria х ananassa», сорт «Азия», Россия), собранные 18 июня 2018 года (Агрохолдинг «Совхоз имени Ленина). Размер ягод составлял 25 - 35 мм в диаметре, с ярко выраженной окраской и характерным ароматом.

\section{Замораживание}

Ягоды замораживали двумя способами. Половину ягод замораживали традиционным способом при минус $30^{\circ} \mathrm{C}$ в условиях конвективного теплообмена. Вторую часть замораживали в тех же условиях, при дополнительном воздействии на ягоды микровибраций, создаваемых в воздушной среде морозильной камеры по определенной программе. В лабораторном устройстве АВАТ20/1-AEF использован цифровой синтезатор частот оригинальной конструкции, имеющий возможность генерации электромагнитных полей мощностью от 1 до $500 \mathrm{BT} / \mathrm{M}^{3} \mathrm{c}$ пакетами одно и двух полярных прямоугольных импульсов в диапазонах частот 10 мГц - 5000 кГц. В замороженных ягодах исследовали микроструктуру и структурномеханические характеристики.

\section{Вакуумная сублимационная сушка}

Вакуумную сублимационную сушку ягод осуществляли на сублимационном лабораторном стенде СВП-0.36. (Семёнов, Краснова, 2018, 292 с.).

Замороженные ягоды размещали на двух металлических противнях, каждый вариант заморозки на отдельном противне. Температура сублимации составляла минус $30 \pm 1^{\circ} \mathrm{C}$, температура на этапе досушки была равной 38 $40{ }^{\circ} \mathrm{C}$.

Длительность цикла высушивания контролировали по датчикам, вставленным в ягоды. Общее время высушивания составило 14-16 часов в зависимости от размера ягод. Массовая доля влаги в высушенных ягодах составляла в среднем $1,7 \%$. В замороженных и сублимированных ягодах исследовали микроструктуру и структурномеханические характеристики. Общая схема замораживания и сублимационной сушки ягод представлена на рисунке 1.

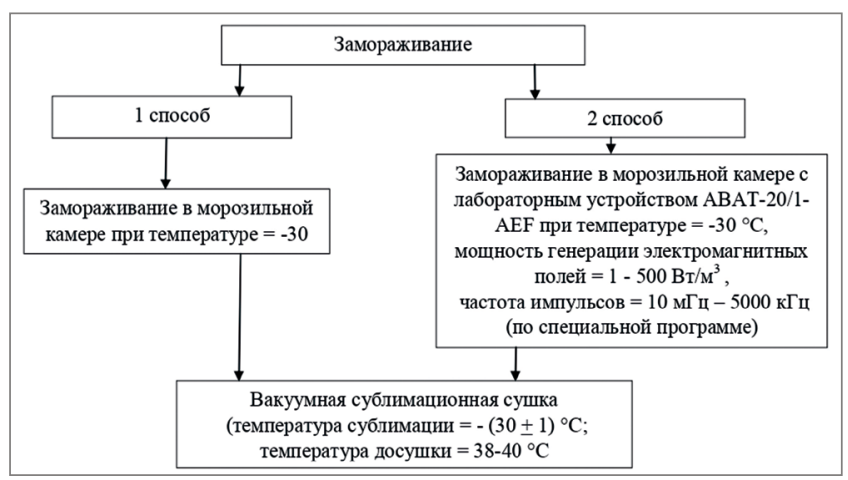

Рисунок 1. Схема производства ягод клубники.

\section{Микроструктурные исследования}

Для микроструктурного исследования замороженной клубники с целью определения степени разрушения тканей при разных режимах замораживания применяли следующую методику (Хвыля, 2016, с. 2-5.; Хвыля, Гиро, 2015, 240 с.). Из ягод без размораживания и отепления вырезали кусочки размером $20 \times 20 \times 10$ мм, которые монтировали на предметные столики криостата. Максимально быстро, чтобы избежать размораживания и изменения микроструктурной организации тканей образцы переносили в камеру замораживающего микротома MIKROM 525 с установленной температурой минус $20^{\circ} \mathrm{C}$. Толщина изготавливаемых срезов составляла около 25 мкм. Полученные срезы монтировали на предметные стекла, переносили в комнатные условия и подсушивали. Затем срезы окрашивали гематоксилином Эрлиха и свежим водноспиртовым эозином. Препараты заключали в глицерин-желатин. Анализ структуры клубники и ее фотографирование проводили с использованием светового микроскопа AxioImager.A1 (Carl Zeiss, Germany). Обработку иллюстративного материала осуществляли с помощью программы ACDS 8 PRO.

\section{Исследования пенетрации и предельного напряжения с,двига}

Замороженные ягоды дефростировали перед определением значений пенетрации и предельного напряжения сдвига. Дефростацию осуществляли посредством естественного отепления ягод при комнатной температуре $22-23^{\circ} \mathrm{C}$.

Полное размораживание ягод достигалось в этих условиях через 2,5-3 часа. Значения пенетрации и предельного напряжения сдвига определяли при комнатной температуре. Ягоды клубники 
фиксировали на измерительной платформе и проводили измерения на самой высокой точке ягоды клубники, поэтому небольшие различия в геометрии поверхности вызывали наименьший эффект. Также все ягоды не имели рельефных различий. Измерения проводили с помощью моторизованного устройства для испытания материалов (пенетрометр ПМДП), оснащенного тензодатчиком на $100 \mathrm{H}$ и цилиндрическим конусом с углом вершины $60{ }^{\circ} \mathrm{C}$. Измеряли глубину погружения индентора и сопротивление продукта погружению индентора в течение 60 секунд.

Величину пенетрации определяли по формуле Ребиндера П.А.:

$\mathrm{P}=\mathrm{k} \cdot \mathrm{m} / \mathrm{h}^{2}$,

где $\mathrm{k}$ - коэффициент, зависящий от угла конуса (k $=2.1 \mathrm{H} / \mathrm{кг})$;

m - масса конуса со штангой $(50.69 * 10-3$ кг);

$\mathrm{h}$ - глубина погружения конуса, м

Предельное напряжение сдвига определяли по аналогичной формуле, где $\mathrm{h}$ - глубина погружения конуса в течение 60 секунд.

\section{Исследование водопоглощения}

Степень гидратации сублимированных образцов ягод $(\Delta)$ определяли по изменению массы клубники до и после регидратации путем погружения ягод в емкость с водой комнатной температуры на 5-7 часов, до полного увлажнения. Затем ягоды вынимали, давали стечь лишней влаге и взвешивали:

$$
\Delta=\frac{m_{2}-m_{1}}{m_{1}} \times 100,
$$

где

$\mathrm{m}_{1}$ - масса клубники до регидратации, г

$\mathrm{m}_{2}$ - масса клубники после регидратации, г

\section{Исследование сорбционных свойств}

Гигроскопичность сублимированных образцов ягод $(\varphi)$ оценивали по изменению массы клубники, находящейся в помещении при комнатной температуре $22-23^{\circ} \mathrm{C}$ и влажности окружающего воздуха 68\%. Взвешивание ягод производилось непосредственно после окончания сублимационной сушки, а затем через каждые 24 часа в течение трех суток:

$$
\varphi=\frac{m_{4}-m_{3}}{m_{3}} \times 100,
$$

где

$\mathrm{m}_{3}$ - масса клубники непосредственно после окончания сублимационной сушки, г $\mathrm{m}_{4}$ - масса клубники через каждые 24 часа в течение трех суток, $\Gamma$

\section{Органолептическая оценка сублимированных ягод}

Органолептическую оценку сухих и восстановленных после регидратации сублимированных ягод клубники проводили согласно ГОСТ 32896-2014. Фрукты сушеные. Общие технические условия. Ягоды восстанавливали путем погружения в воду комнатной температуры до полного их обводнения. Далее ягоды извлекали из воды и располагали на сетчатой поверхности для стекания лишней влаги. После чего проводили их органолептическую оценку.

\section{Статистическая обработка данных}

Статистическую обработку экспериментальных данных проводили с помощью метода математической статистики.

Среднее арифметическое значение: $M=\frac{\sum N}{h}$

Среднее квадратичное отклонение:

$\sigma=\sqrt{\frac{\sum(N-M)^{2}}{h-1}}$

Средняя квадратичная ошибка: $m=\frac{\sigma}{\sqrt{h-1}}$

Критерийдостоверностисредней арифметической:

$t=\frac{M}{m}$

Критерий достоверности между двумя средними арифметическими:

$$
t_{\sigma}=\frac{M_{1}-M_{2}}{\sqrt{m_{1}^{2}+m_{2}^{2}}}
$$

где $\mathrm{N}-$ величина значения каждого наблюдения; h - число наблюдений.

\section{Результаты и их обсуждение}

Анализ микроструктуры тканей ягод, замороженных традиционным способом, показал, что по всей толщине образца, включая внешнюю часть ягод и их глубокие слои, сформировались крупные кристаллические структуры, не окрашиваемые гистологическими красителями. Отмечено, что материал, не воспринимающий использованные красители, 


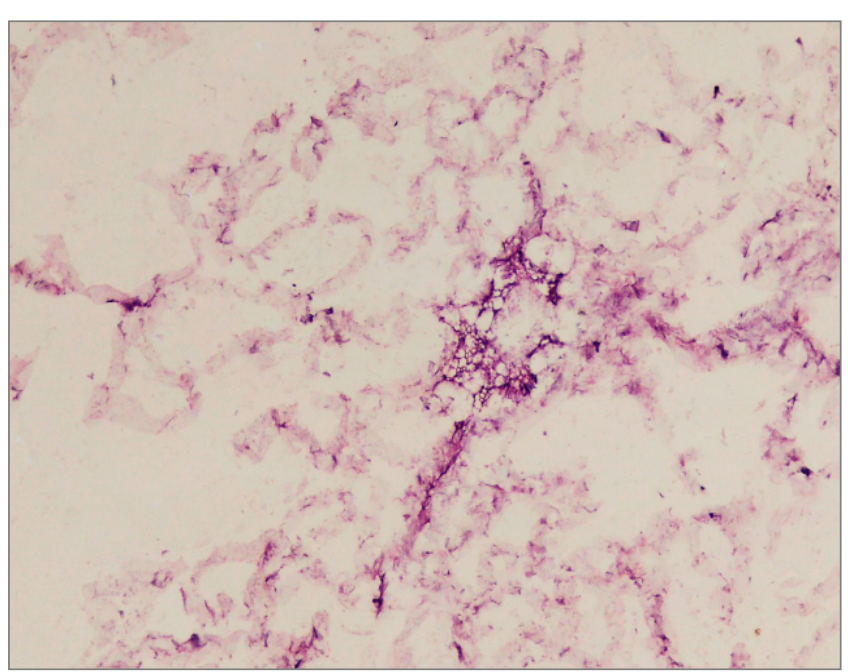

$a$

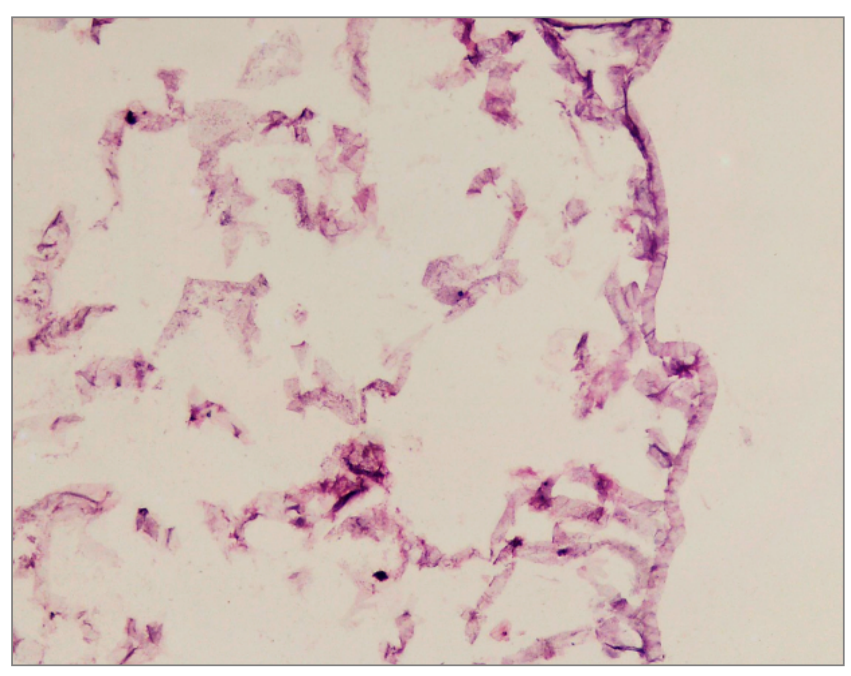

$\sigma$

Рисунок 2. Микроструктура тканей ягоды клубники замороженной традиционным способом. Ув. объектив 20x. а - внутренней части, б - наружной поверхности.

образуется из цитоплазматического содержимого при замораживании ягод (рисунок 2a).

В образцах клубники, замороженной традиционным способом наблюдалось частичное разрушение клеточных стенок как наружной части ягод, так и клеток, формирующих основную массу плода (рис. 2). Использование традиционного режима замораживания привело к фрагментации клеточных оболочек при визуальной оценке препаратов ориентировочно на $60-70 \%$ от общего количества внешних клеточных структур. Более прочные клетки сосудистой системы ягод разрушались в меньшей степени.

Анализ изменений микроструктуры тканей ягод клубники, замороженной с помощью микровибрации, проведенный в аналогичных условиях, показал, что по всему объему замороженных ягод, включая их внешнюю часть и более глубокие слои, сформировались крупные структуры кристаллизованной влаги. Так же, как и в случае применения традиционного режима замораживания, в клетках произошли процессы деструкции клеточного материала, проявляющиеся визуально, прежде всего, в частично разрушении клеточных стенок. В то же время степень наблюдаемых деструктивных изменений микроструктуры тканей ягод при использовании данного режима существенно меньше по сравнению с традиционным режимом замораживания и при визуальной оценке препаратов составила ориентировочно $25-35 \%$ от общего количества внешних клеточных структур. Снижение степени разрушений отмечено как на внешней части ягод, так и в более глубоких слоях тканей плода (рис. 3).

Срезы сублимированной клубники, замороженной традиционным способом и с помощью микровибрации, представлены на рисунке 4.

Анализ структурных особенностей сублимированной клубники показал, что срез ягод, замороженных с дополнительной обработкой микровибрации даже в глубине сублимированной ягоды демонстрирует существенно большую сохранность клеточных стенок. Он характеризуется отчетливыми, сохранными и более контрастными клеточными стенками при более мелких цитоплазматических полостях, утративших воду в процессе сублимации.

Для подтверждения микроструктурных изменений проведены исследования по определению структурно-механических характеристик ягод клубники дефростированных после заморозки и регидратированных после сублимационной сушки. Результаты представлены в таблице 1.

Данные таблицы свидетельствуют о том, что прочность как ягод, замороженных традиционным способом, так и ягод, замороженных с наложением микровибрации после дефростации значительно снижается, по сравнению со свежими ягодами. Отмечено, что в ягодах, замороженных с помощью микровибрации, значения исследуемых показателей более высокие по сравнению с традиционно замороженной клубникой, что свидетельствует о лучшей сохранности структуры ягод. Однако разница в показателях невелика. 


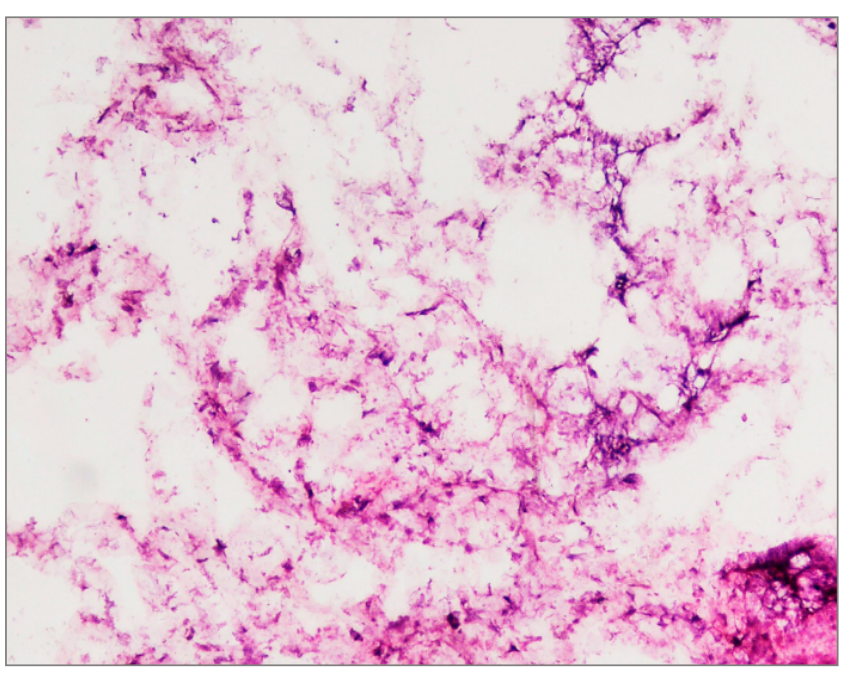

$a$

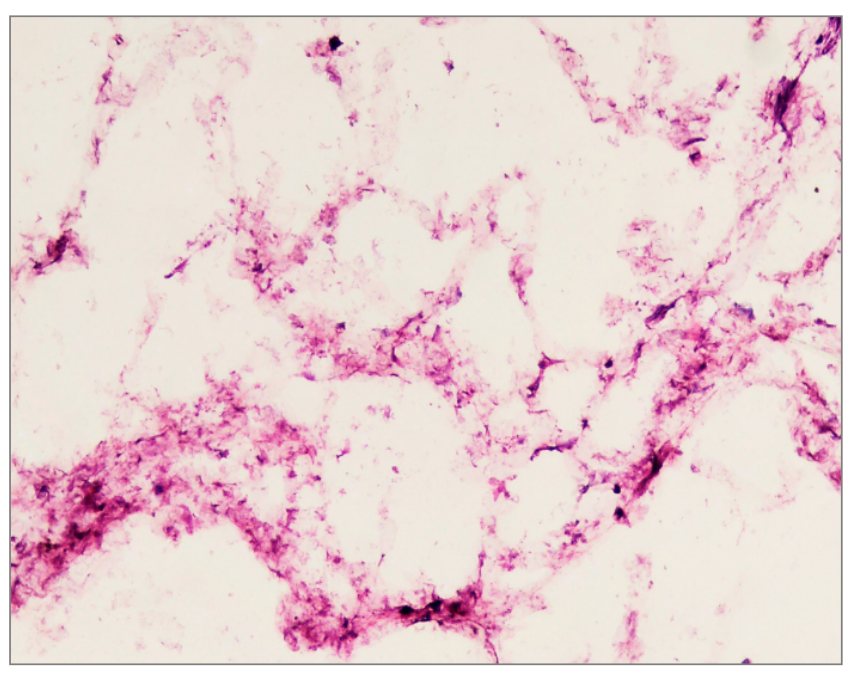

$\sigma$

Рисунок 3. Микроструктура тканей ягоды клубники, замороженной с микровибрацией. Ув. объектив 20х, а - внутренняя часть, б - наружная поверхность.

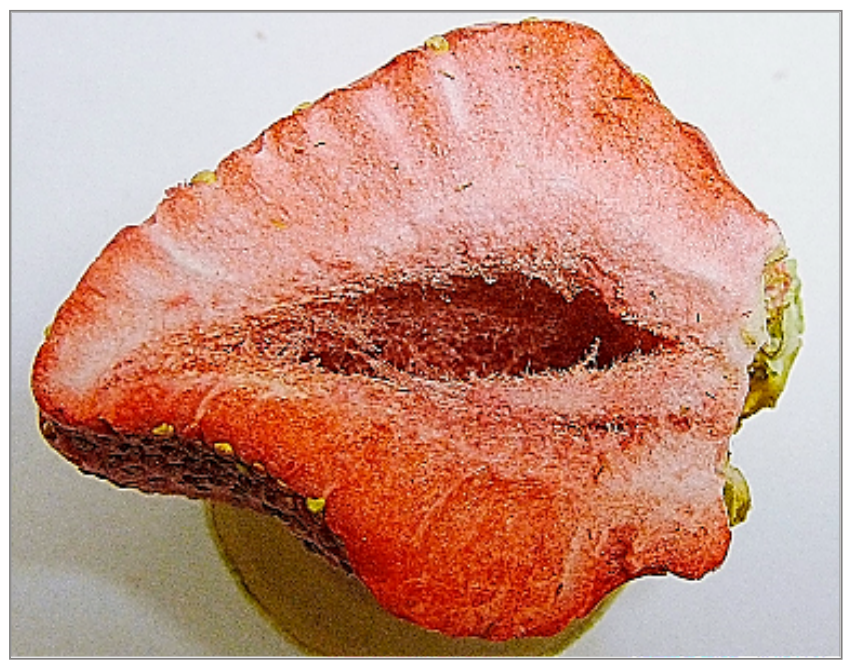

$a$

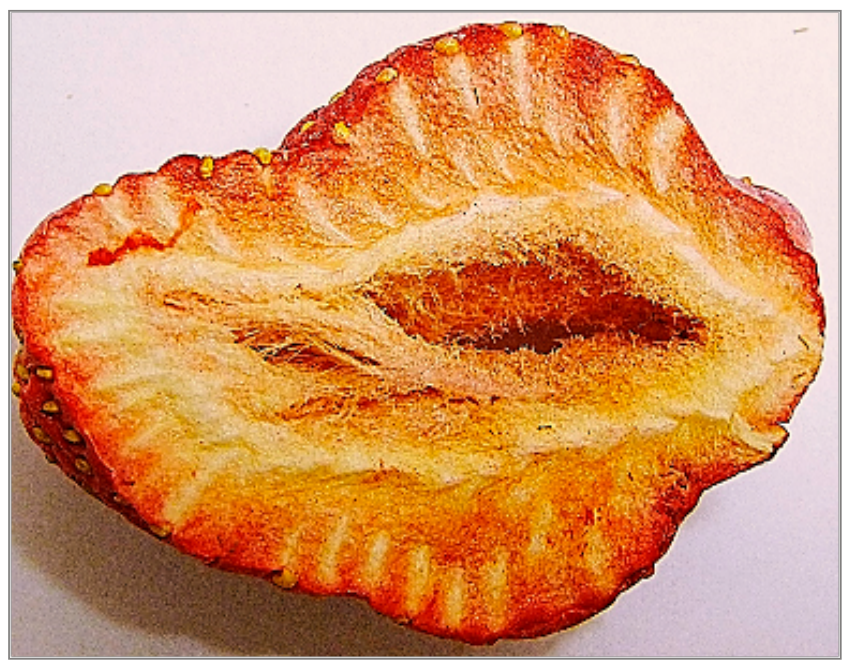

б

Рисунок 4. Срез ягоды сублимированной клубники Ув. 5х: а - предварительно замороженные традиционным способом; б - предварительно замороженные с микровибрацией.

Таблица 1

Структурно-механические показатели ягод клубники

\begin{tabular}{|c|c|c|}
\hline & $\begin{array}{l}\text { Пенетрацияа } \\
\text { кПа }\end{array}$ & $\begin{array}{l}\text { Предельное напряжение } \\
\text { сдвига }{ }^{\text {a, }} \text { кПа }\end{array}$ \\
\hline Свежие ягоды & $15,50 \pm 0,61$ & $10,41 \pm 0,20$ \\
\hline Ягоды, дефростированные после традиционной заморозки & $0,61 \pm 0,03$ & $0,41 \pm 0,12$ \\
\hline Ягоды, дефростированные после заморозки с микровибрацией & $0,71 \pm 0,13$ & $0,48 \pm 0,03$ \\
\hline $\begin{array}{l}\text { Регидратированные сублимированные ягоды, предварительно } \\
\text { замороженные традиционным способом }\end{array}$ & $0,49 \pm 0,14$ & $0,42 \pm 0,17$ \\
\hline $\begin{array}{l}\text { Регидратированные сублимированные ягоды, предварительно } \\
\text { замороженные с микровибрацией }\end{array}$ & $0,55 \pm 0,03$ & $0,47 \pm 0,15$ \\
\hline
\end{tabular}

а Усредненные данные по 15 ягодам каждого вида. 
Аналогичная зависимость показателей выявлена при исследовании сублимированных образцов клубники. Механическая прочность сублимированной клубники, предварительно замороженной с микровибрацией, оказалась выше на 8-10\% по сравнению с сублимированными ягодами, предварительно замороженными традиционным способом.

Ещё одной важной характеристикой структуры сублимированных продуктов являются сорбционные свойства, такие как степень гидратации при восстановлении и скорости поглощения влаги из окружающей среды (гигроскопичность). Данные по уровню регидратации сублимированных ягод клубники представлены в таблице 2 .

После регидратации в течение 5 часов масса сублимированных ягод, замороженных традиционным способом, увеличилась на 73,4\%. Масса ягод, подверженные заморозке с дополнительной микровибрацией увеличилась, лишь до 67,7\%. Такая разница не является значительной и связана с тем, что более мелкая капиллярная структура сухих ягод, подверженных микровибрации, препятствует проникновению влаги внутрь в центр ягоды. Далее ягоды находились в воде ещё 2 часа и степень увлажнения ягод обоих вариантов замораживания оказалась практически одинаковой и равной $75 \%$.

Результаты исследования сорбционной способности сублимированных ягод представлены на рисунке 5

В условиях промышленного производства исключительно важную роль играет поглощение влаги сублимированными ягодами из окружающей среды. Этот параметр влияет на выбор технологии упаковки, допустимого времени нахождения ягод на открытом воздухе без упаковки, а также типа упаковочного материала. Исследования гигроскопичности клубники показали, что сублимированная клубника, замороженная с наложением микровибрации, увеличивается в массе за счёт естественного поглощения влаги из воздуха более интенсивно. Для обеспечения сохранности качества высушенных сублимированных ягод их следует упаковывать в

Таблица 2

Уровень поглощения влаги сублимированными ягодами при погружении в воду комнатной температуры

\begin{tabular}{|c|c|c|c|c|}
\hline Образец & $\begin{array}{l}\text { Средняя масса образцов } \\
\text { сублимированных ягод, г }\end{array}$ & $\begin{array}{c}\text { Средняя масса } \\
\text { восстановленных } \\
\text { образцов, г }\end{array}$ & $\begin{array}{c}\text { Масса } \\
\text { поглощенной } \\
\text { влаги, г }\end{array}$ & $\begin{array}{c}\text { Доля поглощенной } \\
\text { влаги, \% к общей } \\
\text { массе }\end{array}$ \\
\hline $\begin{array}{l}\text { Сублимированные } \\
\text { ягоды, предварительно } \\
\text { замороженные } \\
\text { традиционным } \\
\text { способом }\end{array}$ & $2,81+0,14$ & $10,71+0,2$ & $7,9+0,1$ & $73,4+0,17$ \\
\hline $\begin{array}{l}\text { Сублимированные } \\
\text { ягоды, предварительно } \\
\text { замороженные с } \\
\text { микровибрацией }\end{array}$ & $2,31+0,13$ & $7,23+0,14$ & $4,9+0,2$ & $67,7+0,15$ \\
\hline
\end{tabular}

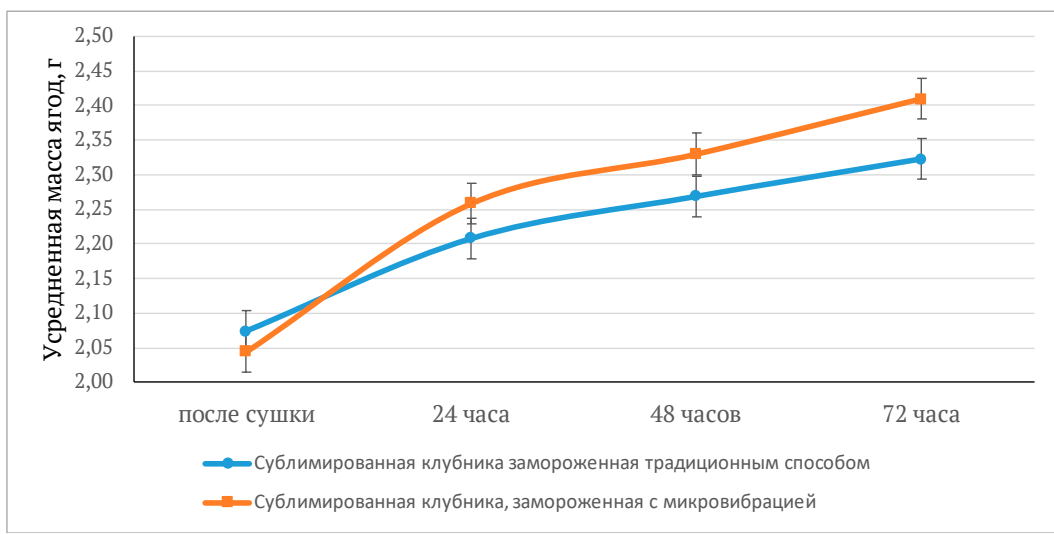

Рисунок 5. Изменение массы сублимированных ягод в процессе хранения на открытом воздухе при температуре $22-23{ }^{\circ} \mathrm{C}$ и относительной влажности $68 \%$. 
свето-газо-непроницаемую металлизированную полимерную пленку. Такая закономерность является еще одним доказательством факта формирования микрокристаллической структуры и, как следствие, более мелких капилляров в высушенных ягодах. Полученные данные соответствуют известной закономерности увеличения сорбционной способности сухих капиллярно-пористых тел по мере уменьшения размеров капилляров, что приводит к пропорциональному увеличению площади поглощения влаги (Поповский, Бантыш, Ивасюк, 1975, с. 336.; Sagara, 2001, с. 183-190.; Segura, Oyarzún, 2012, c. 2102-2109.; Harnkarnsujarit, Kawai, Watanabe, Suzuki, 2016, c. 10-20.).

Конечной целью получения сухих сублимированных ягод является их использование в пищевой промышленности как самостоятельного продукта, либо в составе рецептур различных пищевых продуктов. В соответствие с этим, проведена органолептическая оценка сублимированных сухих и восстановленных исследуемых ягод.

При дегустации сухих сублимированных ягод до регидратации дегустаторы отметили несколько более яркую окраску у сублимированных ягод после замораживания в обычном режиме. На разрезе (предварительно свежие ягоды были разрезаны пополам, до начала эксперимента) у сублимированных ягод после акустической заморозки лучше сохранилась естественная структура тканей ягод клубники. Сублимированные ягоды двух вариантов представлены ниже на рисунке 6. Дегустаторы не выявили различий во

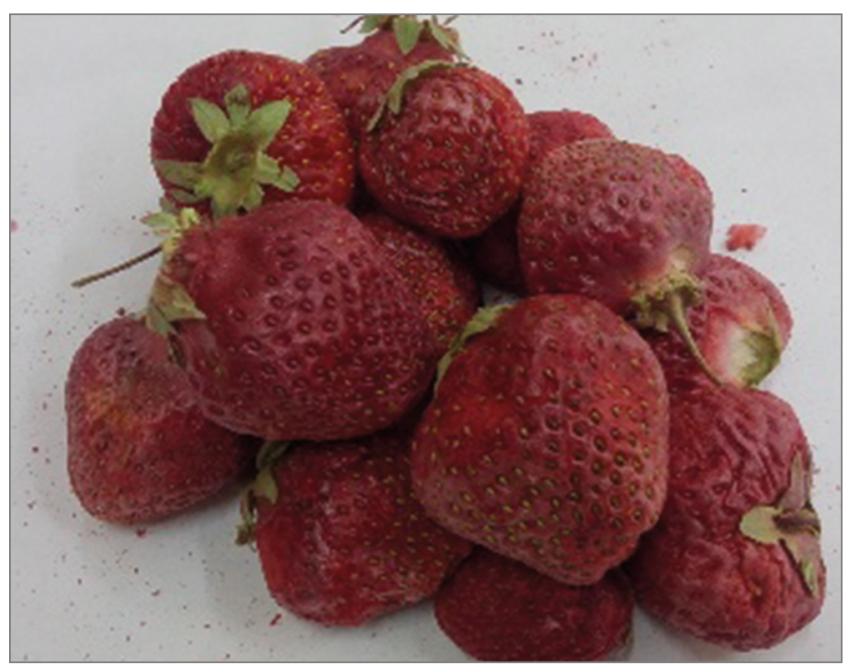

$a$ вкусе и аромате исследуемых образцов.

При органолептической оценке восстановленных сублимированных ягод после регидратации, как и в образцах до регидратации, дегустаторы не выявили заметных отличий между образцами. Дегустаторы улавливали только незначительные отличия по вкусу и цвету в одном или в другом варианте образца. При этом отмечена несколько более плотная консистенция у ягод, предварительно замороженных с микровибрацией.

\section{Выводы}

Отличительной особенностью предложенной технологии замораживания является дополнительное воздействие на ткани объекта в процессе заморозки акустических волн, передаваемых через воздушную окружающую среду и вызывающих в тканях микровибрации. В замороженных ягодах формируется мелкокристаллическая структура льда, обеспечивающая сохранность тканевых структур. Воспринимаемые поверхностью замораживаемого объекта колебания распространяются внутрь объекта с затуханием тем большим, чем больше расстояние от его поверхности. По мере замораживания внешних частей объекта, скорость распространения колебаний в них увеличивается (скорость механических волн в твердом теле выше примерно в два раза), а затухание уменьшается. Это позволяет в значительной мере нивелировать влияние формы и взаимного расположения замораживаемых материалов на конечный

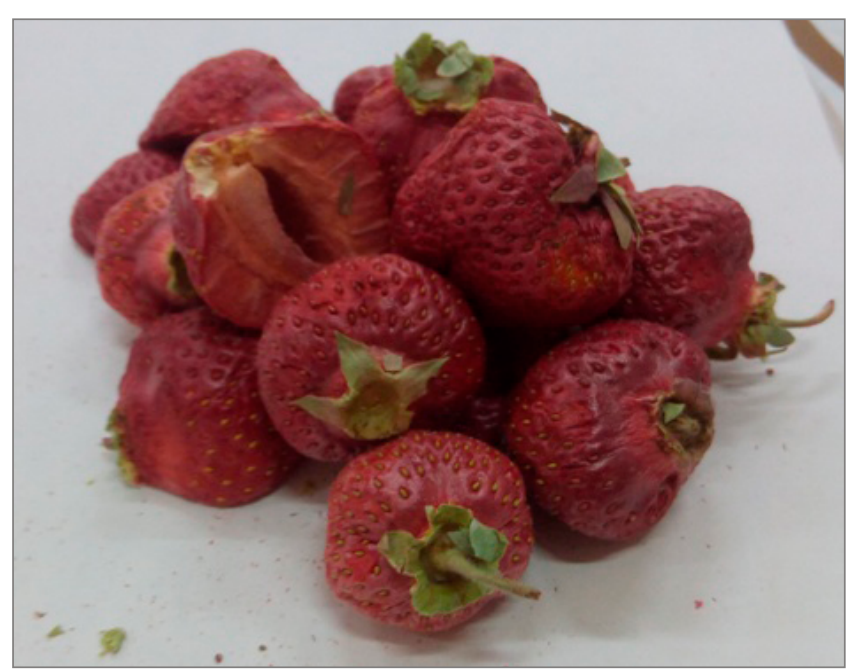

$\sigma$

Рисунок 6. Сухие сублимированные ягоды: а - предварительно замороженные традиционным способом, б - предварительно замороженные с микровибрациеи. 
результат.

Проведенные исследования показали, что замораживаниеягодклубникипридополнительном воздействии на ягоды микровибрацией оказывает положительное влияние как на само замороженное сырьё, так и на его структурные характеристики в высушенном сублимацией состоянии.

Выявлено, что замораживание с применением микровибрации повышает механическую прочность как замороженных, так и сублимированных ягод. Это обстоятельство показывает, что микровибрация позволяет повысить сохранность клубники при ее транспортировке и фасовке.

Исследования, проведенные с использованием ягод клубники, позволяют сделать достаточно обоснованный прогноз о том, что заморозка с микровибрацией в сравнении с традиционной заморозкой ягод мелкого размера с плотной оболочкой (смородина, крыжовник, земляника, клюква и т.д.) позволит получить более значимые преимущества при их сублимационной сушке. Особо важную положительную роль это играет для транспортировки хрупких высушенных ягод.

\section{Литература}

Беляева М.А. Оптимизация технологических регламентов и аппаратурного оформления процесса замораживания плодов (на примере клубники) // Пищевая промышленность. 2017. №3. С.40-43.

Воскобойников В.А. Основные методы производства инстант-продуктов // Пищевая промышленность. 2015. №7. С.21-23.

Дондокова С.А., Битуева Э.Б., Антипов А.В. Использование сублимационной сушки в производстве мясных продуктов // Научное обозрение. Технические науки. 2016. №4. С.3748.

Ишевский А.Л., Давыдов И.А. Замораживание как метод консервирования пищевых продуктов // теория и практика переработки мяса. 2007. №2. С.43-59.

Клочкова Т.И., Шпрах 3.С. Организация, масштабирование и оптимизация производства лиофилизированных препаратов // Российский биотерапевтический журнал. 2006. №3, Том 5. С.115-122.

Колодязная В. С., Кипрушкина Е.И., Бараненко Д.А., Румянцева О.Н., Шестопалова И.А.
Продовольственная безопасность и холодильная технология // Вестник МАХ. 2013. №1. С. 24-28.

Крумликов В.Ю., Остроумов Л.А., Сухих С.А., Кригер О.В. Подбор параметров стабилизации (замораживание и сушка) симбиотического консорциума с целью получения закваски прямого внесения // Техника и технология пищевых производств. 2016. Том. 42. № 3. С. 25-30.

Овчарова Г.П., Абреч М.Ю., Непорожняя Е.Ю. Функциональные продукты сублимационной сушки // Пищевая промышленность. 2008. №2. С.14-15.

Поповский В.Г., Бантыш Л.А., Ивасюк Н.Т. Сублимационная сушка пищевых продуктов растительного происхождения. М.: Пищевая промышленность, 1975. 336 с.

Постольски Я., Груда 3. Замораживание пищевых продуктов. М.: Пищевая промышленность, 1974.607 с.

Похиленко В.Д., Баранов А.М., Детушев К.В. Методы длительного хранения коллекционных культур микроорганизмов и тенденции развития // Известия высших учебных заведений. Поволжский регион. 2009. № 4 (12). С.99-121.

Семёнов Г.В., Булкин М.С., Кузенков А.В. Современные направления научных исследований и технические решения по интенсификации процесса сублимационной сушки в пищевой промышленности, фармпроизводствах и прикладной биотехнологии (Часть 1) // Вестник МАХ. 2015., №1. С.187-202.

Семёнов Г.В., Краснова И.С. Сублимационная сушка пищевых продуктов. М.: ДеЛи плюс. 2018. 292 с.

Сороко О., Усеня Ю. Анализ способов замораживания пищевых продуктов. // Наука и инновации. 2011. №5(99). С.63-67.

Хвыля С.И. Гистологический метод оценки влияния замораживания и хранения на микроструктуру мяса. // Холодильная техника. 2016. №11. С. 2-5.

Хвыля С.И., Гиро Т.М. Оценка качества и биологической безопасности мяса и мясных продуктов микроструктурными методами. Саратов.: СГАУ, 2015. 240 с.

Христюк А.В., Сязин И.Е., Мякинникова Е.И. Технология плодовых и овощных криопорошков // Современные проблемы качества и безопасности продуктов питания в свете требований технического регламента таможенного союза: материалы международной научно-практической конференции (26 марта 2014 г). 2014. C.78-80.

Burmester K., Pietsch A., Eggers R. (2011). A basic investigation on instant coffee production by vacuum belt drying, Procedia Food Science, 
1, $1344-1352 . \quad$ https://doi.org/10.1016/j. profoo.2011.09.199.

Celli G. B., Ghanem A., Su-Ling Brooks M. (2016). Influence of freezing process and frozen storage on the quality of fruits and fruit products, Food Reviews International, 32(3), 280-304. https://doi. org/10.1080/87559129.2015.1075212.

Ciurzyńska A., Lenart A. (2011) Freeze-Drying Application in Food Processing and Biotechnology - a Review, Pol. J. Food Nutr. Sci, 61(3), 165-171. https://doi.org/10.2478/v10222-011-0017-5.

Gaidhani K.A., Harwalkar M., Bhambere D., Nirgude P.S. (2015). Lyophilization / freeze drying - a review, World Journal of Pharmaceutical Research, 4 (8), 516-543.

Harnkarnsujarit N., Kawai K., Watanabe M., Suzuki T. (2016). Effects of freezing on microstructure and rehydration properties of freeze-dried soybean curd, Journal of Food Engineering, 184, 10-20. http://dx.doi.org/10.1016/j.jfoodeng.2016.03.014.

Koroishi E.T., Boss E.A., Wolf Maciel M.R., Filho R.M. (2009). Process development and optimization for freeze-drying of natural orange juice, Journal of Food Process Engineering, 32(3), 425-441. https:// doi.org/10.1111/j.1745-4530.2007.00225.x/

Kozak P., Dziki D., Krzykowski A., Rudy S. (2011). Optimization of energy consumption in the freeze drying process of champignon (Agaricus Bisporus L.), TEKA Kom. Mot. i Energ. Roln. - OL PAN, 134141.
Marques L.G., Silveira A.M., Freire J.T. (2006). Freeze-Drying Characteristics of Tropical Fruits, Drying Technology, 24(4), 457-463. https://doi. org/10.1080/07373930600611919.

Rey L., May J. (2001). Freeze-drying/Lyophilization of pharmaceutical and biological products. Book reviews, Eur. J. Pharm. Biopharm., 51, 163-164.

Sagara Y. (2001). Advances in Transport Phenomena during Freeze-Drying of Food Materials: Fundamentals and Applications, Food Science and Technology Research, 7(3), 183-190. http://dx.doi. org/10.3136/fstr.7.183.

Salazar N.A., Alvarez C., Orrego C.E. (2018). Optimization of freezing parameters for freezedrying mango (Mangifera indica L.) slices, Drying Technology, 36(2), 192-204. https://doi.org/10.108 0/07373937.2017.1315431

Segura L.A., Oyarzún C.A. (2012). Experimental evidence of mass transfer mechanisms during freeze-drying in a capillary porous medium, International Journal of Refrigeration, 35(8), 2102-2109. $\quad$ http://dx.doi.org/10.1016/j. ijrefrig.2012.08.014

Tarafdar A., Shahi N. Ch., Singh A., Sirohi R. (2017). Optimization of Freeze-Drying Process Parameters for Qualitative Evaluation of Button Mushroom (Agaricus bisporus) Using Response Surface Methodology, Journal of Food Quality, 1-6. https:// doi.org/10.1155/2017/5043612 


\title{
The Influence of Micro-Vibration on the Structure of Freeze-Dried Strawberry
}

\author{
Gennadiy V. Semenov \\ Moscow State University of Food Production \\ 11 Volokolamskoe highway, Moscow, 125080, Russian Federation \\ E-mail:sgv47@yandex.ru \\ Irina S. Krasnova \\ Moscow State University of Food Production \\ 11 Volokolamskoe highway, Moscow, 125080, Russian Federation \\ E-mail:ira3891@mail.ru \\ All-Russian Scientific Research Institute of Refrigeration Industry - branch of V.M. Gorbatov \\ Federal Research Center for Food Systems of Russian Academy of Science \\ 12, Kostyakova str., Moscow, 127422, Russian Federation \\ E-mail:gistolab@yandex.ru \\ Dmitry N.Balabolin \\ Acoustic Freezing Ltd. \\ 31, Talalikhina str., Moscow, 109316, Russian Federation \\ E-mail:dbalabolin@gmail.com
}

\begin{abstract}
The structure of freeze-dried strawberries, frozen in the traditional method and freeze-dried strawberries frozen with micro-vibration is shown in this research. Micro-vibrations created in the air of the freezer according to a specific program. A digital frequency synthesizer that generates $250 \mathrm{~W} / \mathrm{m} 3$ electromagnetic field rectangular pulse packets in the frequency bands of 2,500 kHz to $5,000 \mathrm{kHz}$ creates micro-vibrations. Frozen berries were dried on the lab scale freeze dryer SVP-0,36. The primary temperature was minus $30+1{ }^{\circ} \mathrm{C}$. Secondary drying was carried out at a temperature of $38-40{ }^{\circ} \mathrm{C}$. The total duration of the drying cycle was $14-16$ hours, depending on the size of the strawberries. The final moisture content of the freeze-dried strawberries was 1,5-1,7\%. Microstructure, penetration, shear stress, absorption, sorption and sensitive analysis were determined in the freeze-dried samples. It is noted that micro-vibration allows the formation of a fine-crystalline structure of ice and retains the cellular structures in the dried strawberries. Researches of the microstructure showed that freezing with micro-vibration remain $60-70 \%$ cellular structures, compared with $25-30 \%$ of cellular structures preserved during traditional freezing. It was determined that the use of micro-vibration in freezing allows to improve the structural and mechanical characteristics of freeze-dried strawberries and their preservation during packaging and transportation. The sensitive characteristics of the test samples were almost identical. As a result of the research, it was noted that the greatest effect from micro-vibrations was observed for smaller strawberries.
\end{abstract}

Keywords: micro-vibration; strawberry; vacuum freeze drying; microstructure; texture analysis; hygroscopic analysis

\section{References}

Belyayeva M.A. Optimizatsiya tekhnologicheskikh reglamentovi apparaturnogo oformleniya protsessa zamorazhivaniya plodov (na primere klubniki) [Optimization of technological regulations and hardware design of the process of freezing fruits (for example, strawberries)] // Pishchevaya promyshlennost'. 2017, №3. P.40-43.
Voskoboynikov V.A. Osnovnyye metody proizvodstva instant-produktov [The main methods of production of instant-products] // Pishchevaya promyshlennost'. 2015, №7. P.21-23.

Dondokova S.A., Bituyeva E.B., Antipov A.V. Ispol'zovaniye sublimatsionnoy sushki $\mathrm{V}$ proizvodstve myasnykh produktov [The use of freeze-drying for the production of meat products] // Nauchnoye obozreniye. Tekhnicheskiye nauki. 2016, №4. P.37-48.

Ishevskiy A.L., Davydov I.A. Zamorazhivaniye kak 
metod konservirovaniya pishchevykh produktov [Freezing as a method of food preservation] // Teoriya i praktika pererabotki myasa 2007, №2. P.43-59.

Klochkova T.I., Shprakh Z.S. Organizatsiya, masshtabirovaniye i optimizatsiya proizvodstva liofilizirovannykh preparatov[Organization,scaling and optimization of the production of lyophilized preparations] // Rossiyskiy bioterapevticheskiy zhurnal. 2006, №3, Tom 5. P.115-122.

Kolodyaznaya V. S., Kiprushkina Ye.I., Baranenko D.A., Rumyantseva O.N., Shestopalova I.A. Prodovol'stvennaya bezopasnost' i kholodil'naya tekhnologiya [Food safety and refrigeration technology] // Vestnik MAKH. 2013, №1. P. 24-28.

Krumlikov V.YU., Ostroumov L.A., Sukhikh S.A., Kriger O.V. Podbor parametrov stabilizatsii (zamorazhivaniye i sushka) simbioticheskogo konsortsiuma $\mathrm{s}$ tsel'yu polucheniya zakvaski pryamogo vneseniya [Choice of stabilization parameters (freezing and drying) of symbiotic consortium to obtain a starter of direct inoculation.] // Tekhnika i tekhnologiya pishchevykh proizvodstv. 2016. Tom. 42. № 3. S. 25-30.

Ovcharova G.P., Abrech M.YU., Neporozhnyaya Ye.YU. Funktsional'nyye produkty sublimatsionnoy sushki [Functional products of freeze-drying] // Pishchevaya promyshlennost'. 2008, №2. P.14-15.

Popovskiy V.G., Bantysh L.A., Ivasyuk N.T. Sublimatsionnaya sushka pishchevykh produktov rastitel'nogo proiskhozhdeniya. [Freeze drying of foods of plant origin] M.: Pishchevaya promyshlennost', 1975. $336 \mathrm{p}$.

Postol'ski Ya., Gruda Z. Zamorazhivaniye pishchevykh produktov. [Freezing food] M.: Pishchevaya promyshlennost', 1974.607 p.

Pokhilenko V.D., Baranov A.M., Detushev K.V. Metody dlitel'nogo khraneniya kollektsionnykh kul'tur mikroorganizmov i tendentsii razvitiya [Methods of long-term storage of collection cultures of microorganisms and development trends] // Izvestiya vysshikh uchebnykh zavedeniy. Povolzhskiy region. 2009, № 4 (12). P.99-121.

Semenov G.V., Krasnova I.S. Sublimatsionnaya sushka pishchevykh produktov [Freeze-drying food]. M.: DeLi plus, 2018. 292 p.

Semenov G.V., Bulkin M.S., Kuzenkov A.V. Sovremennyye napravleniya nauchnykh issledovaniy $i$ tekhnicheskiye resheniya po intensifikatsii protsessa sublimatsionnoy sushki v pishchevoy promyshlennosti, farmproizvodstvakh i prikladnoy biotekhnologii (Chast' 1) [Modern directions of scientific research and technical solutions for the intensification of the process of freeze-drying in the food industry, pharmaceutical production and applied biotechnology (Part 1)] //
Vestnik MAKH. 2015, №1. P.187-202.

Soroko O., Usenya YU. Analiz sposobov zamorazhivaniya pishchevykh produktov [Analysis of methods for freezing food products] // Nauka i innovatsii. 2011, №5(99). P.63-67.

Khvylya S.I. Gistologicheskiy metod otsenki vliyaniya zamorazhivaniya i khraneniya na mikrostrukturu myasa. [Histological method of assessing the impact of freezing and storage on the microstructure of meat] // Kholodil'naya tekhnika. 2016, №11. P. 2-5.

Khvylya S.I., Giro T.M. Otsenka kachestva i biologicheskoy bezopasnosti myasa i myasnykh produktov mikrostrukturnymi metodami. [Evaluation of the quality and biological safety of meat and meat products by microstructural methods]. Saratov.: SGAU, 2015. 240 p.

Khristyuk A.V., Syazin I.Ye., Myakinnikova Ye.I. Tekhnologiya plodovykh i ovoshchnykh krioporoshkov [Technology of fruit and vegetable cryo-powders] // Sovremennyye problemy kachestva i bezopasnosti produktov pitaniya $\mathrm{v}$ svete trebovaniy tekhnicheskogo reglamenta tamozhennogo soyuza: materialy mezhdunarodnoy nauchno-prakticheskoy konferentsii [Modern problems of quality and food safety in the light of the requirements of the technical regulations of the Customs Union: materials of the international scientific and practical conference], 2014, pp.78-80.

Burmester K., Pietsch A., Eggers R. (2011). A basic investigation on instant coffee production by vacuum belt drying, Procedia Food Science, 1, 1344 - 1352. https://doi.org/10.1016/j. profoo.2011.09.199.

Celli G. B., Ghanem A., Su-Ling Brooks M. (2016). Influence of freezing process and frozen storage on the quality of fruits and fruit products, Food Reviews International, 32(3), 280-304. https://doi. org/10.1080/87559129.2015.1075212.

Ciurzyńska A., Lenart A. (2011) Freeze-Drying Application in Food Processing and Biotechnology - a Review, Pol. J. Food Nutr. Sci, 61(3), 165-171. https://doi.org/10.2478/v10222-011-0017-5.

Gaidhani K.A., Harwalkar M., Bhambere D., Nirgude P.S. (2015). Lyophilization / freeze drying - a review, World Journal of Pharmaceutical Research, 4 (8), 516-543.

Harnkarnsujarit N., Kawai K., Watanabe M., Suzuki T. (2016). Effects of freezing on microstructure and rehydration properties of freeze-dried soybean curd, Journal of Food Engineering, 184, 10-20. http://dx.doi.org/10.1016/j.jfoodeng.2016.03.014.

Koroishi E.T., Boss E.A., Wolf Maciel M.R., Filho R.M. (2009). Process development and optimization for freeze-drying of natural orange juice, Journal of Food Process Engineering, 32(3), 425-441. https:// doi.org/10.1111/j.1745-4530.2007.00225.x/ 
Kozak P., Dziki D., Krzykowski A., Rudy S. (2011). Optimization of energy consumption in the freeze drying process of champignon (Agaricus Bisporus L.), TEKA Kom. Mot. i Energ. Roln. - OL PAN, 134141.

Marques L.G., Silveira A.M., Freire J.T. (2006). Freeze-Drying Characteristics of Tropical Fruits, Drying Technology, 24(4), 457-463. https:/doi. org/10.1080/07373930600611919.

Rey L., May J. (2001). Freeze-drying/Lyophilization of pharmaceutical and biological products. Book reviews, Eur. J. Pharm. Biopharm., 51, 163-164.

Sagara Y. (2001). Advances in Transport Phenomena during Freeze-Drying of Food Materials: Fundamentals and Applications, Food Science and Technology Research, 7(3), 183-190. http://dx.doi. org/10.3136/fstr.7.183.
Salazar N.A., Alvarez C., Orrego C.E. (2018). Optimization of freezing parameters for freezedrying mango (Mangifera indica L.) slices, Drying Technology, 36(2), 192-204. https://doi.org/10.108 0/07373937.2017.1315431

Segura L.A., Oyarzún C.A. (2012). Experimental evidence of mass transfer mechanisms during freeze-drying in a capillary porous medium, International Journal of Refrigeration, 35(8), 2102-2109. ijrefrig.2012.08.014

Tarafdar A., Shahi N. Ch., Singh A., Sirohi R. (2017). Optimization of Freeze-Drying Process Parameters for Qualitative Evaluation of Button Mushroom (Agaricus bisporus) Using Response Surface Methodology, Journal of Food Quality, 1-6. https:// doi.org/10.1155/2017/5043612 